\title{
Effect of carbon substrate and aeration on nitrate reduction and expression of the periplasmic and membrane-bound nitrate reductases in carbon-limited continuous cultures of Paracoccus denitrificans Pd1222
}

\author{
Heather J. Sears, Stephen Spiro and David J. Richardson
}

Author for correspondence: David J. Richardson. Tel: +44 1603 593250. Fax: +441603592250. e-mail: d.richardson@uea.ac.uk

Centre for Metalloprotein Spectroscopy and Biology, School of Biological Sciences, University of East Anglia, Norwich NR4 7TJ, UK
The expression and in situ activity of the membrane-bound and periplasmic nitrate reductases have been assayed in Paracoccus denitrificans Pd1222 grown under a range of aeration regimes in malate-limited or butyrate-limited chemostat cultures. In butyrate-limited cultures the expression of periplasmic nitrate reductase and the rate of in situ nitrate reduction were high at all oxygen concentrations measured between $0 \%$ and $100 \%$ air saturation. By contrast, in malate-limited cultures expression of the periplasmic nitrate

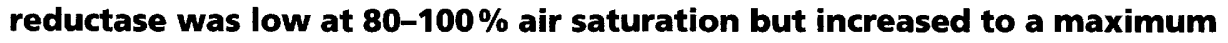
between $\mathbf{2 0} \%$ and $\mathbf{5 0} \%$ air saturation. Aerobic nitrate reduction was much higher in butyrate-limited than in malate-limited cultures, demonstrating a significant role for this process during butyrate metabolism. The rate of nitrate respiration increased in both the malate- and butyrate-limited cultures as aerobic metabolism switched completely to anaerobic metabolism. Expression of the membrane-bound nitrate reductase could be detected in butyratelimited chemostat cultures maintained at an oxygen level of $100 \%$ air saturation. No membrane-bound nitrate reductase was detectable under similar conditions in malate-limited cultures but expression was detected at oxygen concentrations of $\mathbf{5 0} \%$ air saturation and below. Taken together, the results show that the nature of the carbon substrate and oxygen concentration can both influence expression of the periplasmic and membrane-bound nitrate reductases. The conditions under which expression of the periplasmic nitrate reductase and aerobic nitrate respiration are maximal can be rationalized in terms of a role for the periplasmic nitrate reductase in dissipating excess reductant generated during oxidative metabolism of reduced carbon substrates.

Keywords: nitrate reductase, aerobic nitrate respiration, denitrification, redox balancing, Paracoccus denitrificans

\section{INTRODUCTION}

Many bacterial species from diverse genera have the ability to utilize nitrate as an alternative respiratory electron acceptor to oxygen (Zumft, 1992; Berks et al., 1995). In many cases this is confined to anaerobic conditions, but some bacteria have been reported to respire nitrate at high oxygen concentrations (Kuenen $\&$ Robertson, 1988; Robertson \& Kuenen, 1990). This 'aerobic' nitrate respiration has been studied in most detail in Paracoccus denitrificans strain GB17 (also known as LMD82.5; Robertson \& Kuenen, 1984, 1990; Bell et al., 1990, 1993; Richardson \& Ferguson, 1992). This strain was first isolated from a paper-milling wastetreatment plant and was originally named Thiosphaera pantotropha (Robertson \& Kuenen, 1983). P. denitrificans GB17 can express two types of respiratory nitrate reductase; a membrane-bound enzyme and a periplasmic enzyme (Bell et al., 1990; Berks et al., 1995). The membrane-bound enzyme has an active site in the 
cytoplasm and can catalyse the reduction of chlorate whereas the periplasmic enzyme is highly specific for nitrate (Bell et al., 1990, 1993; Berks et al., 1994). The periplasmic enzyme catalyses aerobic nitrate respiration whilst expression and activity of the membrane-bound enzyme are normally restricted to anaerobic conditions (Bell et al., 1990, 1993; Richardson \& Ferguson, 1992). The recent reclassification of T. pantotropha as a strain of $P$. denitrificans (Ludwig et al., 1993) has placed an aerobic denitrifier into a species that for many years was considered a paradigm for anaerobic denitrification. The extent to which strains of $P$. denitrificans other than GB17 can respire nitrate aerobically has been debated. Robertson and co-workers could not detect significant levels of aerobic denitrification in strain LMD22.21 (Robertson \& Kuenen, 1984, 1992; Robertson et al., 1988), but it was detected by Lloyd and co-workers in strain NCIMB 8944 (Davies et al., 1989; Lloyd et al., 1987). A periplasmic nitrate reductase has been identified in strains Pd1222 (parent strain DSM 413) and LMD22.21 (Sears et al., 1993; Sears, 1995), but aerobic nitrate respiration could not be detected in bacteria harvested from batch cultures and assayed as a nongrowing suspension.

Recently, 30 bacteria that express the periplasmic nitrate reductase, including members of the genera Pseudomonas and Aeromonas have been isolated from soils and freshwater sediments (Carter et al., 1995a, b). Most, but not all, of these isolates are capable of nitrate respiration under aerobic conditions when grown in batch culture on butyrate-containing medium. Thus, it seems most probable that the ability of a bacterium to express the periplasmic nitrate reductase provides the biochemical apparatus needed for aerobic nitrate respiration, but that other factors related to cellular metabolism determine whether electrons are diverted to the nitrate reductase from the oxidase systems. In this respect it is notable that although $P$. denitrificans GB17 was originally reported to catalyse the complete reduction of nitrate to dinitrogen (via nitrite, nitric oxide and nitrous oxide) in the presence of oxygen (Robertson \& Kuenen, 1984) subsequent attempts to measure significant rates of aerobic nitrite reduction have been unsuccessful (Thomsen et al., 1993; Moir et al., 1995). This may be accounted for by the strain losing the need to respire nitrogen oxides extensively as a consequence of up-regulation of cytochrome $a a_{3}$ oxidase during repeated subculturing (Robertson et al., 1995; Stouthamer et al., 1997). The physiological role of aerobic nitrate respiration is probably related to a need to dissipate excess reductant under certain metabolic conditions (Richardson \& Ferguson, 1992; Berks et al., 1995). In accordance with this view the route of electron transport from quinol to nitrate via the periplasmic enzyme is not predicted to be coupled to energy conservation. This contrasts with the more highly coupled membrane-bound nitrate reductase where one positive charge $\left(\mathrm{q}^{+}\right)$is likely to be translocated per electron transferred from $\mathrm{UQH}_{2}$ [i.e. $\mathrm{q}^{+} \uparrow / \mathrm{e}^{-}\left\langle\mathrm{QH}_{2} \rightarrow\right.$ $\left.\mathrm{NO}_{3}{ }^{-}\right)=1$ ] (Berks et al., 1995). The factors that could lead to a cellular redox imbalance include the oxidative metabolism of highly reduced carbon substrates, metabolism under energy-sufficient conditions and metabolism under oxygen-limited conditions. Understanding the effect of these parameters on aerobic nitrate respiration will be important if the process is to realize its potential in aerobic waste-treatment processes (Robertson \& Kuenen, 1992). In the present study the Pd1222 strain of $P$. denitrificans, which has not previously been reported to respire nitrate aerobically, but which can express a periplasmic nitrate reductase (Sears et al., 1993), has been studied in carbon-limited chemostat cultures. The influence of carbon substrate and oxygen concentration on the expression of the periplasmic and membranebound nitrate reductases has been studied. Aerobic nitrate reduction has been measured and the conditions under which this occurs provide support for the view that aerobic nitrate respiration corrects cellular redox imbalance.

\section{METHODS}

Operation of continuous cultures. Paracoccus denitrificans strain Pd1222 (resistant to spectinomycin and rifampicin) was obtained from N. Harms (Amsterdam; de Vries et al., 1989) and was grown in the minimal medium of Harms et al. (1985). Continuous cultures were grown in minimal medium with $25 \mathrm{mM} \mathrm{KNO}$ and $5 \mathrm{mM}$ carbon substrate (butyrate or Lmalate). $\mathrm{CaCl}_{2}$ (73 $\mathrm{g} \mathrm{ml}^{-1}$ final concentration) was added after sterilization through a $0.22 \mu \mathrm{M}$ filter attached to a piece of tubing which fed into the medium reservoir and was removed after the $\mathrm{CaCl}_{2}$ had been added. The vessel was inoculated with $5 \mathrm{ml}$ of an aerobic overnight culture grown with spectinomycin and rifampicin $\left(50 \mu \mathrm{g} \mathrm{ml}^{-1}\right.$ final concentration) and operated in batch mode overnight. The following day the culture was switched to continuous mode. The dissolved oxygen concentration in the culture was measured with a polarographic $\mathrm{pO}_{2}$ electrode (Ingold). The electrode was calibrated after sterilization when the vessel was ready to be inoculated. A dissolved oxygen controller with integral air pump was used in conjunction with the oxygen meter to control the dissolved oxygen in the culture. Anaerobic conditions were maintained by sparging the vessel with oxygen-free nitrogen. For growth at dissolved oxygen concentrations less than $25 \%$ the vessel was sparged with a mixture of air and nitrogen. Fluctuations in dissolved oxygen were monitored by a chart recorder connected to the oxygen meter recorder output. The $\mathrm{pH}$ of the culture was controlled by a two-way pump used in conjunction with a combined glass electrode (Ingold). The $\mathrm{pH}$ of the culture was maintained between 7.2 and 7.6 by the addition of $10 \%(\mathrm{v} / \mathrm{v})$ phosphoric acid and $10 \%(\mathrm{w} / \mathrm{v}) \mathrm{NaOH}$. The chemostats were regularly checked for contamination using light and electron microscopy and by streaking culture samples on agar plates.

The culture was judged to have reached steady state after at least four vessel-volume changes. To confirm that the chemostats were operating under carbon limitation, anaerobic and aerated cultures were pulsed with an additional $10 \mathrm{mM}$ of carbon substrate at the end of an operational run. This resulted in a rapid increase in the biomass level to approximately double that obtained under the carbon-limited condition.

Analytical procedures. Samples were withdrawn through a narrow-bore tube leading to a collecting bottle which was placed on ice immediately after sampling. The samples were 
dealt with according to the following protocol. Three lots of $30 \mathrm{ml}$ culture were centrifuged for $15 \mathrm{~min}$ and the supernatant stored at $-20^{\circ} \mathrm{C}$ for nitrate and nitrite analyses. The cell pellets were washed twice in $10 \mathrm{mM}$ phosphate buffer $(\mathrm{pH} 7.5)$ by resuspending in $10 \mathrm{ml}$ buffer and centrifuged at $6000 \mathrm{~g}$ for $15 \mathrm{~min}$ at $4{ }^{\circ} \mathrm{C}$. The first cell pellet was resuspended in $1 \mathrm{ml}$ phosphate buffer $(\mathrm{pH} 7.5)$ and used for intact cell assays of nitrate reductase activity. The second cell pellet was resuspended in $5 \mathrm{ml}$ buffer $\left(0.5 \mathrm{M}\right.$ sucrose, $3 \mathrm{mM} \mathrm{Na}{ }_{2}$ EDTA and $100 \mathrm{mM} \mathrm{Tris} / \mathrm{HCl} \mathrm{pH} \mathrm{8.0)} \mathrm{and} \mathrm{used} \mathrm{to} \mathrm{prepare} \mathrm{periplasm} \mathrm{and}$ membrane fractions as described previously (Sears et al., 1993). The final cell pellet was resuspended in $3 \mathrm{ml}$ phosphate buffer and the biomass determined after drying overnight at $80^{\circ} \mathrm{C}$. The nitrate reductase activities of intact cells, periplasm and membrane fractions were measured spectrophotometrically using reduced methyl viologen $\left(\mathrm{MV}^{+}\right)$or reduced benzyl viologen $\left(\mathrm{BV}^{+}\right)$as electron donor (Sears et al., 1993). Absorption spectra were collected using an Aminco DW2000 spectrophotometer. The steady-state rate of nitrate reduction was calculated from the difference between the influent and steady-state levels of nitrate and given as a function of the steady-state biomass. The rate of nitrite accumulation was calculated from the level of nitrite assayed in the chemostat at steady state and given as a function of the steady-state biomass.

\section{RESULTS}

\section{Nitrate consumption and nitrate reductase activity in malate-limited and butyrate-limited chemostat cultures of $P$. denitrificans Pd1222 maintained at a range of aeration levels}

Previous batch-culture studies with $P$. denitrificans Pd1222 have demonstrated that expression of the periplasmic nitrate reductase (Nap) is highest following growth on reduced carbon substrates (Richardson \& Ferguson, 1992; Sears et al., 1993; Sears, 1995). Malate $\left(\mathrm{C}_{4} \mathrm{H}_{6} \mathrm{O}_{5}\right)$ and butyrate $\left(\mathrm{C}_{4} \mathrm{H}_{8} \mathrm{O}_{2}\right)$ were selected as relatively oxidized and reduced $\mathrm{C}_{4}$ carbon substrates, respectively. The specific activity of Nap has previously been shown to be 60-fold higher in cultures grown on butyrate ( $2800 \mathrm{nmol} \mathrm{MV} \mathrm{MV}^{+}$oxidized $\mathrm{min}^{-1} \mathrm{mg}$ protein ${ }^{-1}$ ) than in those grown on malate $\left(45 \mathrm{nmol} \mathrm{MV^{+ }}\right.$ oxidized $\mathrm{min}^{-1} \mathrm{mg}$ protein ${ }^{-1}$ ) (Sears et al., 1993).

The maximum specific growth rates $\left(\mu_{\max }\right)$ for bacteria grown on malate and butyrate in batch culture were $0.550 \mathrm{~h}^{-1}$ and $0.097 \mathrm{~h}^{-1}$, respectively. Thus, the dilution rates (D) that could be maintained in butyrate-limited chemostat cultures were much lower than those that could be maintained in malate-limited chemostat cultures. A preliminary series of experiments was undertaken to investigate the effect of dilution rates on the specific rate of Nap production $\left(q_{\mathrm{Nap}}\right)$ in air-saturated chemostats. In both butyrate- and malate-limited cultures $q_{\text {Nap }}$ was maximal at intermediate dilution rates; $\mathrm{D}=0.22 \mathrm{~h}^{-1}$ in malate-limited cultures and $\mathrm{D}=$ $0.05 \mathrm{~h}^{-1}$ in butyrate-limited cultures.

The biomass yield of the butyrate-limited cultures was $590 \pm 55 \mathrm{mg}$ dry wt $\mathrm{l}^{-1}$ [118 mg dry wt (mmol butyrate $\left.)^{-1}\right]$. This was higher than for the malate-limited cultures, in which the yield was $396 \pm 42 \mathrm{mg}$ dry wt $\mathrm{l}^{-1}$ $\left.[80 \mathrm{mg} \text { dry wt (mmol malate })^{-1}\right]$. In both cases the

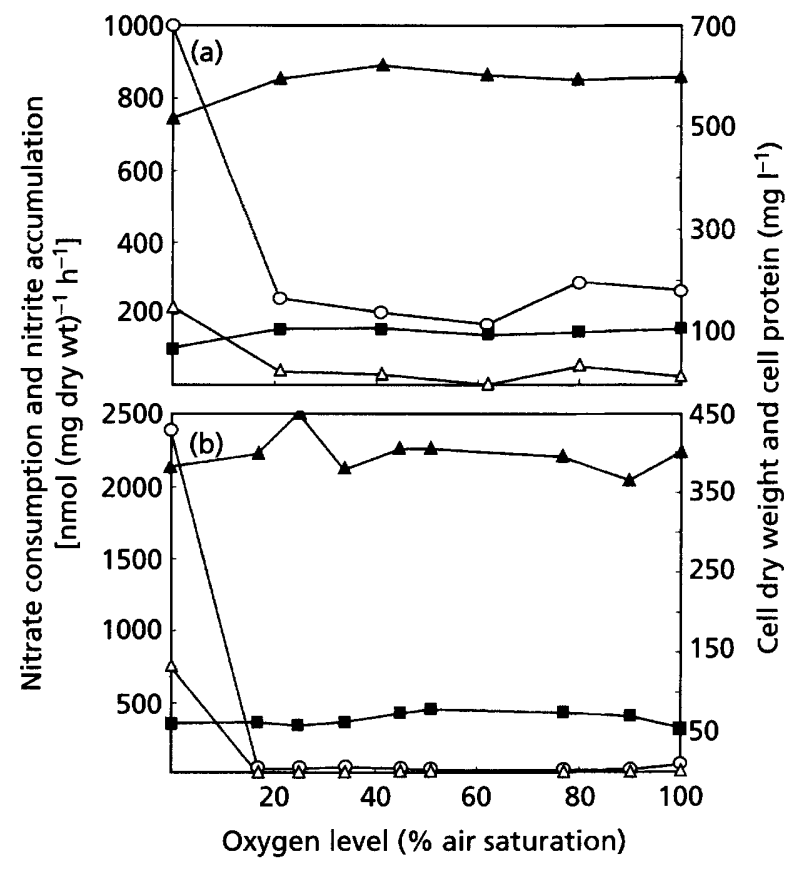

Fig. 1. The effect of oxygen on the reduction of nitrate $(0)$, accumulation of nitrite $(\triangle)$, and quantities of cell biomass $(\mathbf{A})$ and cell protein ( $\boldsymbol{D}$ ) in (a) butyrate-limited and (b) malatelimited chemostat cultures of $P$. denitrificans Pd1222. The percentage variation (given in brackets) for each aeration level was: butyrate, $100 \%$ air saturation ( $0 \%$ variation), 80 (3), 40 (1), $20(3), 0(0)$; and malate, $100(0), 90(0), 77(3), 51(2), 45(5)$, $34(6), 25(13), 17(9), 0(0)$.

biomass yield was not significantly affected by oxygen. The protein yield of the butyrate-limited cultures was $104 \pm 20 \mathrm{mg} \mathrm{l}^{-1}\left[21 \mathrm{mg}\right.$ (mmol butyrate) $^{-1}$ ] (Fig. 1a). The protein content of the malate-limited cultures was $67 \pm 14 \mathrm{mg} \mathrm{l}^{-1}\left[13.5 \mathrm{mg}\right.$ (mmol malate) $\left.{ }^{-1}\right]$ (Fig. 1b). The mean biomass: protein ratio was $5 \cdot 5: 1$ for the butyratelimited cultures and 5.0:1 for the malate-limited cultures. Polyhydroxyalkanoate was not measured quantitatively but electron micrographs revealed small quantities of the storage polymer in the butyrate-limited cells and virtually none in the malate-limited cells. This could account for the small difference in the biomass: protein ratios of the two cultures.

To assess the extent of electron flux through the nitrate reductase(s) the steady-state consumption of nitrate and production of nitrite by the cultures were measured. In butyrate-limited cultures maintained at oxygen levels of $20-100 \%$ air saturation the steady-state nitrate consumption was around $230 \mathrm{nmol}(\mathrm{mg} \text { dry wt})^{-1} \mathrm{~h}^{-1}$ (Fig. 1a). Ammonia was present as nitrogen source and was detectable at millimolar levels at all oxygen concentrations (data not shown). Ammonium represses the assimilatory nitrate reductase (Sears et al., 1997), which suggests that aerobic nitrate respiration, rather than nitrate assimilation, was being measured. The rate of nitrite accumulation was maximally $8 \mathrm{nmol}$ (mg dry $\mathrm{wt})^{-1} \mathrm{~h}^{-1}$ and so was much lower than the rate of nitrate consumption. This suggested that nitrite reductase was 


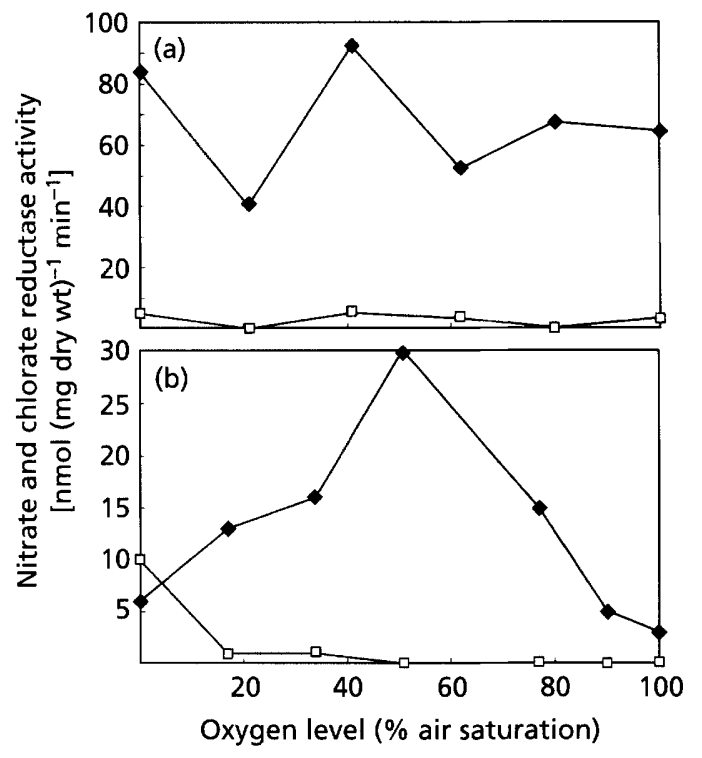

Fig. 2. The effect of oxygen on expression of the periplasmic nitrate reductase in (a) butyrate-limited and (b) malate-limited chemostat cultures of $P$. denitrificans Pd1222. $\downarrow$, Nitrate reductase activity; $\square$, chlorate reductase activity. The variation in the aeration level at each point is given in Fig. 1.

also active under these conditions and reduced most of the nitrite produced by the nitrate reductase. These cultures can thus be considered to be catalysing aerobic denitrification, that is the conversion of nitrogen oxyanions to gaseous nitrogen oxides in the presence of high levels of oxygen. Under anaerobic conditions the rate of nitrate consumption rose to $1200 \mathrm{nmol}$ (mg dry $\mathrm{wt})^{-1} \mathrm{~h}^{-1}$ as metabolism switched completely to anaerobic denitrification. Under these conditions nitrite accumulated at a rate of $230 \mathrm{nmol}(\mathrm{mg} \text { dry wt) })^{-1} \mathrm{~h}^{-1}$ indicating that nitrite reduction no longer matched nitrite production by nitrate reductase (Fig. 1a).

In the aerated malate-limited cultures nitrate consumption was very low between oxygen levels of $15 \%$ and $90 \%$ air saturation [around $20 \mathrm{nmol}(\mathrm{mg} \text { dry wt })^{-1} \mathrm{~h}^{-1}$ ] and was matched by nitrite accumulation (Fig. 1b). This indicated that nitrite produced from nitrate was not being reduced further and that aerobic nitrate respiration was around 10-fold lower than in the butyratelimited cultures. Under anaerobic conditions the rate of nitrate consumption rose to around $2400 \mathrm{nmol}$ (mg dry $w t)^{-1} h^{-1}$ (Fig. 1b).

\section{The effect of oxygen on expression of the periplasmic and membrane-bound nitrate reductases in malate-limited and butyrate-limited chemostat cultures of $P$. denitrificans Pd1222}

To resolve the contribution made by the periplasmic (Nap) and membrane-bound (Nar) nitrate reductases to total cellular nitrate reductase activity at different oxygen levels, bacteria were fractionated into periplasmic and membrane fractions and each fraction

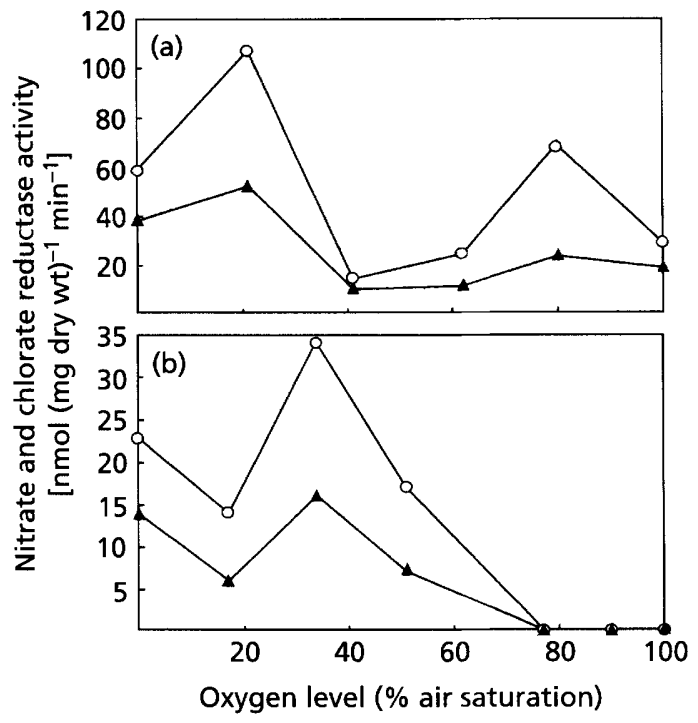

Fig. 3. The effect of oxygen on expression of the membranebound nitrate reductase in (a) butyrate-limited and (b) malatelimited chemostat cultures of $P$. denitrificans Pd1222. $\Delta$, Nitrate reductase activity; $O$, chlorate reductase activity. The variation in the aeration level at each point is given in Fig. 1.

assayed for nitrate and chlorate reductase activity using $\mathrm{MV}^{+}$as electron donor. In butyrate-limited cultures the nitrate reductase activity in the periplasm (Nap) expression was not significantly affected by oxygen and was $72 \pm 22 \mathrm{nmol}(\mathrm{mg} \mathrm{dry} \mathrm{wt})^{-1} \mathrm{~min}^{-1}$ (Fig. 2a). In the malate-limited cultures the specific activity of Nap in the periplasmic fractions varied over a 10 -fold range [3$30 \mathrm{nmol}$ (mg dry $\mathrm{wt})^{-1} \mathrm{~min}^{-1}$ ] and was maximal at intermediate oxygen levels (Fig. 2b). At $80-100 \%$ air saturation Nap specific activity was approximately 20fold higher in the butyrate-limited than in the malatelimited cultures (compare Figs 2a and b). Purified Nap has a maximum specific activity of $100 \mu \mathrm{mol}$ (mg protein) ${ }^{-1} \min ^{-1}$ (Berks et al., 1994); thus, the Nap expression observed is around $0.4 \%$ of the total cell protein in the cells from butyrate-limited cultures.

In batch cultures of $P$. denitrificans $P d 1222$ expression of the membrane-bound nitrate reductase (Nar) is normally confined to anaerobic conditions (Bell et al., 1990; Sears et al., 1993). However, analysis of the nitrate reductase activity of membranes prepared from airsaturated butyrate-limited cultures of $P$. denitrificans $\mathrm{Pd} 1222$ revealed expression of $\mathrm{Nar}$ (Fig. 3a). The specific activity was $17 \mathrm{nmol}(\mathrm{mg} \text { dry } \mathrm{wt})^{-1} \mathrm{~min}^{-1}$, approximately fourfold lower than the specific activity of Nap. At oxygen levels of $20 \%$ air saturation the specific activity of Nar was two- to threefold greater than in airsaturated cultures and was comparable to Nap (Fig. 3a).

No significant membrane-bound nitrate reductase activity could be detected in malate-limited cultures maintained at oxygen concentrations of $77 \%, 90 \%$ and $100 \%$ air saturation (Fig. 3b). Membrane-associated nitrate reductase activity could be detected at oxygen 


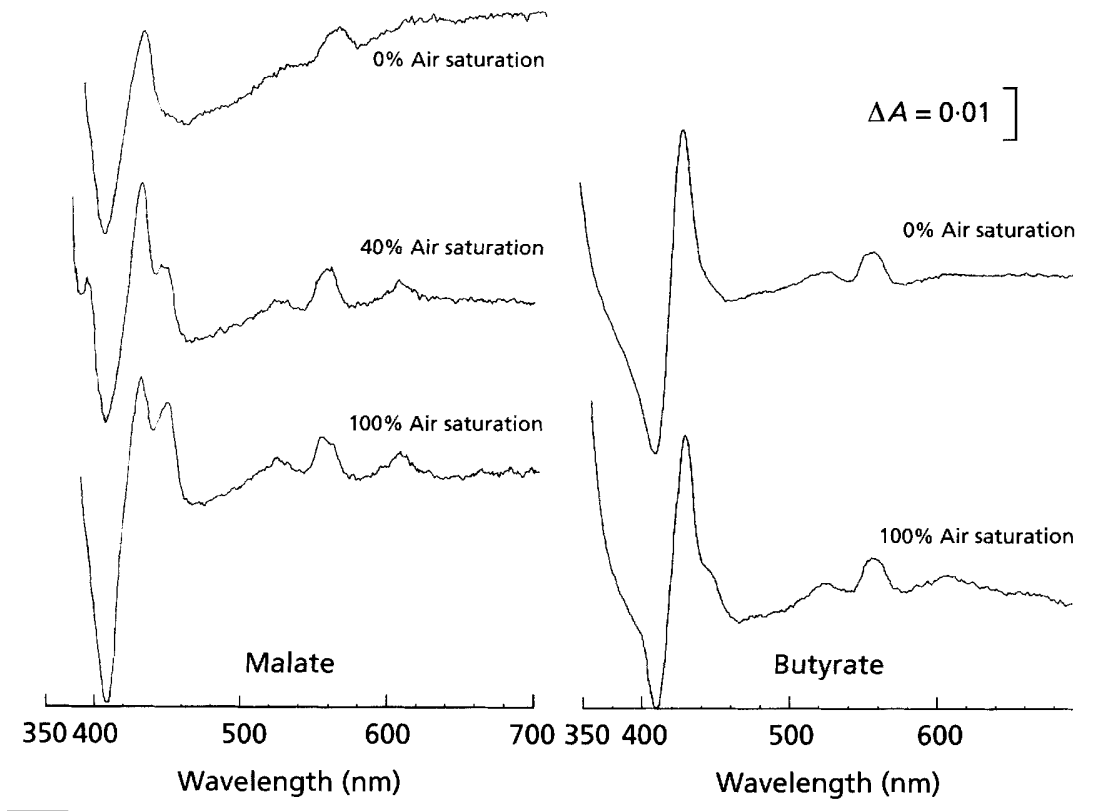

Fig. 4. Dithionite-reduced minus airoxidized difference spectra of membranes prepared from cells of $P$. denitrificans Pd1222 sampled from a malate-limited chemostat maintained at oxygen levels of $100 \%, 45 \%$ and $0 \%$ air saturation and from a butyrate-limited chemostat maintained at oxygen levels of $100 \%$ and $0 \%$ air saturation. concentrations of $50 \%$ air saturation and below and did not vary significantly at any of the aeration levels measured in this range (Fig. $3 \mathrm{~b}$ ).

The membrane-bound nitrate reductase catalyses the reduction of chlorate with a $V_{\max }$ twice that for nitrate (Craske \& Ferguson, 1986). The pattern of specific chlorate reductase activity of the membrane fractions was similar to that of nitrate reductase (Fig. 3). This confirmed that the nitrate reductase activities measured were due to the membrane-bound enzyme (Nar) and not to contamination of the membrane fractions with periplasmic nitrate reductase (Nap), which cannot reduce chlorate. Furthermore, chlorate reductase activities were either absent or very low in the periplasmic fractions (Fig. 2), confirming that there was little or no contamination of these fractions by small membrane fragments and that the enzyme being assayed was the periplasmic nitrate reductase. The exception to this was at $0 \%$ air saturation in the malate-limited cultures (Fig. 2), where some chlorate reductase activity was detected in the periplasm, suggesting contamination from membranes containing Nar. Despite repeating the cell fractionation for this data-point on a number of occasions this contamination persisted.

\section{Spectral analysis of membranes of $P$. denitrificans Pd1222 prepared from cells cultured at different levels of aeration}

Transcription of the Nar operon is under the control of the FnrP protein, which may sense intracellular oxygen and/or the redox state of a cellular component (van Spanning et al., 1997). If FnrP responds to the redox state of the cell, the expression of Nar under highly aerated conditions suggests that the bacteria in the butyrate-limited cultures have a more reduced state than bacteria in the malate-limited cultures. Another protein that is regulated by FnrP is the cytochrome $c b b_{3}$ oxidase, a high-affinity oxidase that is normally expressed under anoxic or micro-oxic conditions (van Spanning et al., 1997; Stouthamer et al., 1997). Expression of oxidases was measured qualitatively from analysis of the reduced minus oxidized difference spectra of membrane fractions. In membranes prepared from cells grown at $100 \%$ air saturation in malate-limited chemostat cultures the main features of the reduced minus oxidized spectra were (i) peaks at $446 \mathrm{~nm}$ and $610 \mathrm{~nm}$ corresponding to absorption peaks of reduced cytochrome $a a_{3}$ oxidase and (ii) peaks at $428 \mathrm{~nm}$ and $550-560 \mathrm{~nm}$ corresponding to absorption maxima of reduced $c$ and $b$ haems, which could be contributed to by the cytochrome $b b_{3}$ oxidase and the cytochrome $c b b_{3}$ oxidase (Fig. 4). The ratio of $428 \mathrm{~nm}$ and $446 \mathrm{~nm}$ peaks was approximately $1: 1$. A similar ratio was observed between these peaks in spectra of membranes prepared from bacteria grown at $90 \%$ and $77 \%$ air saturation (not shown). In membranes prepared from cells grown at oxygen levels of $51 \%$, $45 \%$ (Fig. 4), $34 \%$ and $25 \%$ air saturation, the levels of cytochrome $a a_{3}$ relative to $c$-type and $b$ cytochromes were decreased as judged by a decrease in the $446 \mathrm{~nm}$ peak relative to the $428 \mathrm{~nm}$ peak (Fig. 4). Under anaerobic conditions the $446 \mathrm{~nm}$ peak was barely discernible, suggesting that cytochrome $a a_{3}$ was only present at very low levels (Fig. 4).

Membranes prepared from butyrate-limited cells grown under anaerobic conditions showed similar spectral properties to those of the anaerobic malate-limited cells (Fig. 4). However, the spectrum of membranes prepared from cells grown at an oxygen level of $100 \%$ air saturation in the butyrate-limited cultures did not exhibit the clear $1: 1$ double peak at $428 \mathrm{~nm}$ and $446 \mathrm{~nm}$ that was observed in the membranes from malatelimited cells grown at the same aeration level. Instead, the $100 \%$ air saturation butyrate-limited membranes 
resembled those of the malate-limited cells grown at $45 \%$ air saturation (Fig. 4). The features of these spectra did not change significantly in membranes prepared from cells grown at oxygen levels of $80 \%, 60 \%, 40 \%$ or $20 \%$ air saturation (not shown).

\section{DISCUSSION}

The results presented in this study demonstrate that expression of the periplasmic and membrane-bound nitrate reductases by $P$. denitrificans $\mathrm{Pd} 1222$ can be influenced by the nature of the carbon substrate and oxygen concentration in carbon-limited chemostat cultures. During heterotrophic growth the carbon source serves both as a substrate for oxidative phosphorylation (dissimilatory metabolism) and for assimilation into cellular material. In the overall process of assimilation the carbon substrate is reduced or oxidized to the mean reduced state of the cellular carbon. Assimilation of a highly reduced carbon substrate will therefore result in the generation of more reducing equivalents than assimilation of a relatively oxidized substrate. This could lead to the accumulation of reduced pyridine nucleotides and coenzymes which need to be reoxidized if metabolism is to proceed. The failure to reoxidize reduced pyridine nucleotide will ultimately result in an over-reduction of the $\mathrm{Q} / \mathrm{QH}_{2}$ pool, leading to a restriction in the rate of turnover of Q-dependent redox proteins (e.g. the $Q_{i}$ site of the cytochrome $b c_{1}$ complex). The recycling of coenzymes would normally occur via biosynthesis reactions and oxidative phosphorylation, but if the biosynthetic machinery and the highly coupled aerobic respiratory electron-transport pathways are saturated then alternative recycling mechanisms are needed. These will include the dissipation of reductant by poorly coupled electron transport pathways such as the periplasmic nitrate reductase system.

Assuming a mean biomass composition of $\mathrm{CH}_{2} \mathrm{~N}_{0 \cdot 25} \mathrm{O}_{0 \cdot 5}$ (close to $\mathrm{CH}_{1 \cdot 8} \mathrm{~N}_{0 \cdot 25} \mathrm{O}_{0 \cdot 48}$ measured for $P$. denitrificans; van Verseveld $e t$ al., 1978), the overall assimilation of malate and butyrate with ammonia as nitrogen source, regardless of the precise metabolic pathway, will be:

Malate:

$\mathrm{C}_{4} \mathrm{H}_{6} \mathrm{O}_{5}+\mathrm{NH}_{3}+5\left[\mathrm{H}^{+}+\mathrm{e}^{-}\right] \rightarrow 4 \mathrm{CH}_{2} \mathrm{~N}_{0 \cdot 25} \mathrm{O}_{0 \cdot 5}+3 \mathrm{H}_{2} \mathrm{O}$

Butyrate:

$\mathrm{C}_{4} \mathrm{H}_{8} \mathrm{O}_{2}+\mathrm{NH}_{3} \rightarrow 4 \mathrm{CH}_{2} \mathrm{~N}_{0 \cdot 25} \mathrm{O}_{0 \cdot 5}+3\left[\mathrm{H}^{+}+\mathrm{e}^{-}\right]$

The carbon substrate that is not assimilated into cellular biomass will be dissimilated:

Malate:

$\mathrm{C}_{4} \mathrm{H}_{6} \mathrm{O}_{5}+3 \mathrm{H}_{2} \mathrm{O} \rightarrow 4 \mathrm{CO}_{2}+12\left[\mathrm{H}^{+}+\mathrm{e}^{-}\right]$

Butyrate:

$$
\mathrm{C}_{4} \mathrm{H}_{8} \mathrm{O}_{2}+6 \mathrm{H}_{2} \mathrm{O} \rightarrow 4 \mathrm{CO}_{2}+20\left[\mathrm{H}^{+}+\mathrm{e}^{-}\right]
$$

Even allowing for some variation in the CHNO composition in cells grown on the two carbon substrates, equations (1) and (2) demonstrate that the assimilation of malate consumes reductant whilst the assimilation of butyrate generates reductant. In addition, more reductant is generated per mole of butyrate dissimilated than per mole of malate assimilated [equations (3) and (4)]. Since the butyrate-limited culture was being operated at a lower dilution rate than the malate-limited culture, the rate of carbon metabolism will be lower and there will be a higher maintenance energy requirement (relative to the total energy requirement). Despite this the significant rates of aerobic nitrate and nitrite reduction measured in the butyrate-limited cultures but absent in the malatelimited cultures indicate that the malate-limited cultures were energy-limited whilst the butyrate-limited cultures were energy-sufficient and that surplus energy was dissipated through reduction of the nitrogen oxyanions.

Both the membrane-bound (Nar) and periplasmic (Nap) nitrate reductases were expressed at $100 \%$ air saturation in the butyrate-limited chemostat cultures. The combined activity of Nar and Nap in these bacteria measured with reduced viologen dyes was around 10-20-fold greater than the in vivo steady-state electron flux through the enzymes, as estimated from the rate of nitrate consumption. It is not possible to be certain which enzyme is removing the nitrate as both have sufficient catalytic capacity. The periplasmic enzyme seems the most likely participant, as electron transfer from $\mathrm{QH}_{2}$ to nitrate is not coupled to the generation of a protonmotive force, allowing turnover at higher rates in the presence of a high oxidase-dependent protonmotive force. Furthermore, the barrier of nitrate transport across the membrane does not need to be overcome during nitrate reduction by the Nap system. In the malate-limited cultures, where no Nar could be detected at high aeration levels, the low rate of nitrate reduction must be via the periplasmic system.

The results presented in this work have demonstrated a differential expression of the membrane-bound and periplasmic nitrate reductases. In Escherichia coli both the membrane-bound and periplasmic nitrate reductases are subject to control by the Fnr protein (Spiro \& Guest, 1990; Spiro, 1994). An Fnr homologue, designated FnrP, has been identified in $P$. denitrificans Pd1222, which regulates the membrane-bound but not the periplasmic enzyme (van Spanning et al., 1997; Stouthamer et al., 1997; Berks et al., 1995). Fnr binds an iron-sulphur cluster which undergoes redox chemistry allowing the protein to modulate the rate of transcription in response to the redox state of the cell and/or the level of intracellular oxygen (Lazazzera et al., 1996; Unden et al., 1990; Becker et al., 1996). Thus, the expression of Fnr-dependent systems under aerobic conditions can be envisaged if the cell is in a reduced state. This has been demonstrated in P. denitrificans Pd1222 mutants deficient in the cytochrome $a a_{3}$ oxidase and the cytochrome $b b_{3}$ quinol oxidase, which switch on the FnrP-regulated $c b b_{3}$ oxidase under aerobic conditions (Stouthamer et al., 1997; van Spanning et al., 1997; de Gier et al., 1994). An indication of the reduced state of the cells in the present study can be taken from consideration of the reduced minus oxidized difference spectra of the mem- 
branes prepared from cells taken from the malatelimited and butyrate-limited cultures. These spectra suggest a much higher level of $c$ and $b$-type cytochromes relative to cytochrome $a a_{3}$ in the highly aerated butyratelimited cultures compared to the highly aerated malatelimited cultures. This situation is normally expected at low oxygen levels, wherein the high affinity cytochrome $c b b_{3}$ oxidase which is under FnrP control, is induced. Thus, the spectra indicate that cells growing on butyrate suffer from over-reduction even at high oxygen levels. The expression of the membrane-bound nitrate reductase at all oxygen tensions in butyrate-limited cultures of $P$. denitrificans $\operatorname{Pd} 1222$ is consistent with this view. From the membrane spectra it can be seen that the redox state of the cells grown on butyrate may be similar to that of the cells grown on malate maintained at oxygen levels of $50-25 \%$ air saturation. Accordingly, under these conditions in the malate-limited cultures Nap expression is highest and expression of the membrane-bound nitrate reductase can also be observed.

The data presented in this work suggest that Nap is regulated in response to the redox state of the bacterium. The data do not allow discrimination between transcriptional, translational or post-translational regulation and the components of this regulatory system cannot be speculated upon at this stage. However, it is notable, particularly in the malate-limited cultures, that increased Nap expression does not always coincide with an increase in the rate of electron flux through the periplasmic nitrate reductase. It is likely that bacteria possess a range of tools for dealing with perturbations in cellular redox balance which include heterotrophic nitrification (Robertson \& Kuenen, 1990), reductive polyalkylanoate synthesis (Robertson et al., 1988) and electron flux through poorly coupled quinol oxidases (de Gier et al., 1994). It may be that Nap expression increases in response to a redox signal that also regulates synthesis of other redox-balancing pathways, providing the cell with options for which one to utilize. Thus, under conditions where Nap expression is high but nitrate reduction is low other redox-balancing pathways may be operating.

\section{ACKNOWLEDGEMENTS}

D.J.R. and S.S. are grateful to the BBSRC and the Royal Society for financial support. H. J.S. was the recipient of a BBSRC studentship. We are grateful to Dr Ben Berks and Professor Stuart Ferguson for helpful discussions.

\section{REFERENCES}

Becker, S., Holighaus, G., Gabrielczyk, T. \& Unden, G. (1996). $\mathrm{O}_{2}$ as the regulatory signal for FNR-dependent gene regulation in Escherichia coli. J Bacteriol 178, 4515-4521.

Bell, L. C., Richardson, D. J. \& Ferguson, S. J. (1990). Periplasmic and membrane-bound respiratory nitrate reductases in Thiosphaera pantotropha: the periplasmic enzyme catalyses the first step in aerobic denitrification. FEBS Lett 265, 85-87.

Bell, L. C., Page, M. D., Berks, B. C., Richardson, D. J. \& Ferguson, S. J. (1993). Insertion of transposon Tn5 into a structural gene of the membrane-bound nitrate reductase of Thiosphaera pantotropha results in anaerobic overexpression of periplasmic nitrate reductase activity. J Gen Microbiol 139, 3205-3214.

Berks, B. C., Richardson, D. J., Robinson, C., Reilly, A., Aplin, R. T. \& Ferguson, S. J. (1994). Purification and characterisation of the periplasmic nitrate reductase from Thiosphaera pantotropha. Eur J Biochem 220, 117-124.

Berks, B. C., Ferguson, S. J., Moir, J. W. B. \& Richardson, D. J. (1995). Enzymes and associated electron transfer systems that catalyse the respiratory reduction of nitrogen oxides and oxyanions. Biochim Biophys Acta 1232, 97-173.

Carter, J. P., Richardson, D. J. \& Spiro, S. (1995a). The isolation and characterisation of a strain of Pseudomonas putida that can express a periplasmic nitrate reductase. Arch Microbiol 163, 159-166.

Carter, J. P., Hsiao, Y. H., Spiro, S. \& Richardson, D. J. (1995b). Soil and sediment bacteria capable of aerobic nitrate respiration. Appl Environ Microbiol 61, 2852-2858.

Craske, A. L. \& Ferguson, S. J. (1986). The respiratory nitrate reductase of Paracoccus denitrificans. Molecular characterisation and molecular properties. Eur J Biochem 158, 429-436.

Davies, K. J. P., Lloyd, D. \& Boddy, L. (1989). The effect of oxygen on denitrification in Paracoccus denitrificans and Pseudomonas aeruginosa. J Gen Microbiol 135, 2445-2451.

de Gier, J.-W. L., Lübben, M., Reijnders, W. N. M., Tipker, C. A., Slotboom, D.-J., van Spanning, R. J. M., Stouthamer, A. H. \& van der Oost, J. (1994). The terminal oxidases of Paracoccus denitrificans. Mol Microbiol 13, 183-196.

Harms, N., de Vries, G. E., Maurer, K., Veltkamp, E. \& Stouthamer, A. H. (1985). Isolation and characterisation of Paracoccus denitrificans mutants with defects in the metabolism of one-carbon compounds. J Bacteriol 164, 1064-1070.

Kuenen, J. G. \& Robertson, L. A. (1988). Ecology of nitrification and denitrification. In The Nitrogen and Sulphur Cycles (SGM Symposium no. 42), pp. 161-218. Edited by J. A. Cole \& S. J. Ferguson. Cambridge: Cambridge University Press.

Lazazzera, B. A., Beinert, H., Khoroshilova, N., Kennedy, M. C. \& Kiley, P. J. (1996). DNA-binding and dimerization of the Fe-S containing FNR protein from Escherichia coli are regulated by oxygen. J Biol Chem 271, 2762-2768.

Lloyd, D., Boddy, L. \& Davies, K. J. P. (1987). Persistence of bacterial denitrification under aerobic conditions: the rule rather than the exception. FEMS Microbiol Ecol 45, 185-190.

Ludwig, W., Mittenhuber, G. \& Freidrich, C. G. (1993). Transfer of Thiosphaera pantotropha to Paracoccus denitrificans. Int J Syst Bacteriol 43, 363-367.

Moir, J. W. B., Richardson, D. J. \& Ferguson, S. J. (1995). The expression of redox proteins of denitrification in Thiosphaera pantotropha grown with oxygen, nitrate, and nitrous oxide as electron acceptors. Arch Microbiol 164, 43-49.

Richardson, D. J. \& Ferguson, S. J. (1992). The influence of carbon substrate on the activity of the periplasmic nitrate reductase in aerobically grown Thiosphaera pantotropha. Arch Microbiol 157, 535-537.

Robertson, L. A. \& Kuenen, J. G. (1983). Thiosphaera pantotropha gen. nov. sp. nov., a facultatively anaerobic, facultatively autotrophic sulphur bacterium. J Gen Microbiol 129, 2847-2855.

Robertson, L. A. \& Kuenen, J. G. (1984). Aerobic denitrification : a controversy revived. Arch Microbiol 139, 351-354.

Robertson, L. A. \& Kuenen, J. G. (1990). Combined heterotrophic nitrification and aerobic denitrification in Thiosphaera pantotropha and other bacteria. Antonie Leeuwenhoek 57, 139-152. 
Robertson, L. A. \& Kuenen, J. G. (1992). Nitrogen removal from water and waste. In Microbial Control of Pollution (SGM Symposium no. 48), pp. 227-267. Edited by J. C. Fry, G. M. Gadd, R. A. Herbert, C. W. Jones \& I. A. Watson-Craik. Cambridge: Cambridge University Press.

Robertson, L. A., van Niel, E. W. J., Torremans, R. A. M. \& Kuenen, J. G. (1988). Simultaneous nitrification and denitrification in aerobic chemostat cultures of Thiosphaera pantotropha. Appl Environ Microbiol 54, 2812-2818.

Robertson, L. A., Dalsgaard, T., Revsbech, N. P. \& Kuenen, J. G. (1995). Confirmation of aerobic denitrification in batch cultures, using gas chromatography and N-15 mass spectrometry. FEMS Microbiol Ecol 18, 113-119.

Sears, H. J. (1995). The periplasmic nitrate reductase of Paracoccus denitrificans: physiological and genetic studies. $\mathrm{PhD}$ thesis, University of East Anglia, UK.

Sears, H. J., Ferguson, S. J., Richardson, D. J. \& Spiro, S. (1993). The identification of a periplasmic nitrate reductase in Paracoccus denitrificans. FEMS Microbiol Lett 113, 107-112.

Sears, H. J., Little, P. J., Richardson, D. J., Spiro, S., Berks, B. C. \& Ferguson, S. J. (1997). Identification of an assimilatory nitrate reductase in mutants of Paracoccus denitrificans GB17 deficient in nitrate respiration. Arch Microbiol 167, 61-66.

van Spanning, R. J. M., de Boer, A. P. N., Reijnders, W. N. M., Westerhoff, H. V., Stouthamer, A. H. \& van der Oost, J. (1997). FnrP and NNR of Paracoccus denitrificans are both members of the FNR family of transcriptional activators but have distinct roles in respiratory adaptation in response to oxygen limitation. Mol Microbiol 23, 893-907.

Spiro, S. (1994). The FNR family of transcriptional regulators. Antonie Leeuwenhoek 66, 23-26.
Spiro, S. \& Guest, J. R. (1990). FNR and its role in oxygenregulated gene expression in Escherichia coli. FEMS Microbiol Lett 75, 399-428.

Stouthamer, A. H., de Boer, A. P. N., van der Oost, J. \& van Spanning, R. J. M. (1997). Emerging principles of inorganic nitrogen metabolism in Paracoccus denitrificans and related bacteria Antonie Leeuwenhoek 71, 33-41.

Thomsen, J. K., Lønsmann Iversen, J. J. \& Cox, R. P. (1993). Interactions between respiration and denitrification during growth of Thiosphaera pantotropha in continuous culture. FEMS Microbiol Lett 110, 319-324.

Unden, G., Trageser, M. \& Duchene, A. (1990). Effect of positive redox potential $(>+400 \mathrm{mV})$ on expression of anaerobic respiratory enzymes of Escherichia coli. Mol Microbiol 4, 315-319.

van Verseveld, H. W. \& Stouthamer, A. H. (1978). Growth yields and the efficiency of oxidative phosphorylation during autotrophic growth of Paracoccus denitrificans on methanol and formate. Arch Microbiol 118, 21-26.

de Vries, G. E., Harms, N., Hoogendijk, J. \& Stouthamer, A. H. (1989). Isolation and characterisation of Paracoccus denitrificans mutants with increased conjugation frequencies and pleiotropic loss of a (nGATCn) DNA-modifying property. Arch Microbiol $152,52-57$.

Zumft, W. G. (1992). The denitrifying prokaryotes. In The Prokaryotes, 2nd edn., pp. 554-582. Edited by A. Balows, H. G. Trüper, M. Dworkin, W. Harder \& K.-H. Schleifer. Berlin: Springer.

Received 9 June 1997; revised 13 August 1997; accepted 18 August 1997. 